\title{
Müllerian adenosarcoma of cervix in a young nulliparous woman
}

\section{Sameera Begum Kader Ibrahim, Prasanta Kumar Deka, Tham Seng Woh}

\begin{abstract}
Introduction: Müllerian adenosarcoma is a rare tumor of the cervix. Typical adenosarcoma presents as a large polypoid mass occupying the endometrial cavity. It occurs mainly in postmenopausal women. It is a very rare occurrence in adolescent girls and young adults. To date, this neoplasm has been reported in only 10 young adult and adolescent girls. The tumor tends to recur locally rather than to disseminate to distant areas. Case Report: A 23-year-old female, single, sexually not active and nulliparous presented to a private hospital for complaints of prolonged menstruation of six months duration. Speculum examination revealed cauliflower like growth arising from the cervix. Polypectomy and hysteroscopic diagnostic dilatation and curettage was done. Histopathology of the specimens showed cervical polyp with features of welldifferentiated Müllerian adenosarcoma of low grade with endometrium in secretory phase. A total abdominal hysterectomy, bilateral salpingooophorectomy, omentectomy, pelvic and
\end{abstract}

Sameera Begum Kader Ibrahim¹, Prasanta Kumar Deka², Tham Seng Woh ${ }^{3}$

Affiliations: ${ }^{1} \mathrm{MD}$, Professor, Department of Obstetrics and Gynaecology, Melaka Manipal Medical College, Melaka, Malaysia; ${ }^{2} \mathrm{MD}$, Associate Professor, Department of Obstetrics and Gynaecology, Melaka Manipal Medical College, Melaka, Malaysia; ${ }^{3} \mathrm{MD}$, Head of the Department, Department of Obstetrics and Gynaecology, Melaka Government Hospital, Melaka, Malaysia.

Corresponding Author: Dr. Sameera Begum, Professor, Department of O\&G, Melaka Manipal Medical College, Melaka-75150, Malaysia; Ph: 006-0176765047; Email: sameerabgm@yahoo.com

Received: 02 March 2013

Accepted: 21 June 2013

Published: 01 November 2013 paraaortic lymphadenectomy, appendicectomy were done. Conclusion: Adenosarcoma most commonlyarisesfrom theendometrium, butsome cases from the endocervix. In postmenarchal adolescents, these polypoid tumors usually arise from the cervix, in contrast to postmenopausal women in whom they usually arise from the endometrium. Cervical Müllerian adenosarcoma usually treated by radical hysterectomy even in younger age group as there is higher chance of recurrence later following conservative surgical management. The presence of malignancy should be always kept in mind while resecting a cervical polyp.

Keywords: Müllerian adenosarcoma, Endometrium, Cervix, Polyp, Vaginal bleeding

$$
* * * * * * * * *
$$

Ibrahim SBK, Deka PK, Woh TS. Müllerian adenosarcoma of cervix in a young nulliparous woman. International Journal of Case Reports and Images 2013;4(11):602-606.

$$
* * * * * * * * *
$$

doi:10.5348/ijcri-2013-11-390-CR-4

\section{INTRODUCTION}

Müllerian adenosarcoma of the uterus is a rare tumor containing benign glandular epithelial and malignant mesenchymal elements. Typical adenosarcoma is a lowgrade tumor, presents as a large polypoid mass occupying the endometrial cavity and may protrude into the vaginal cavity [1]. This tumor was first described by Clement and Scully in 1974 as Müllerian adenosarcoma. It occurs mainly in the uterus of postmenopausal women but can occur in adolescents and young adults [2]. Extrauterine 
locations such as ovaries, cervix, vagina, peritoneum and Pouch of Douglas also had been reported [3-6]. To date, this neoplasm has been reported in only 10 young adult and adolescent girls. There is a case report of a 10-year-old girl, the youngest female ever reported, who was diagnosed with Müllerian adenosarcoma arising from the endocervix [7]. We report one case of Müllerian adenosarcoma of the cervix because of its rarity.

\section{CASE REPORT}

A 23-year-old female, single, sexually not active and nulliparous presented to a private hospital for complaints of prolonged menstruation of six months duration associated with continuous dull suprapubic pain with gradual abdominal distension. There was a history of scanty, thick, yellowish, foul-smelling vaginal discharge with pruritus on and off not responded to medications. She was admitted in a private hospital three times in last six months due to symptomatic anemia and received blood transfusion during each admission. There was no significant past medical or surgical illnesses and no family history of malignancy.

On general examination, severe pallor was present. Other vital signs were normal. Breast and thyroid examinations were normal. On per abdominal examination, no abnormality was detected. Initial trans-abdominal ultrasound scan did not reveal any abnormalities.

During the third admission, a trans-abdominal ultrasound scan was repeated which showed endometrial thickness of $18 \mathrm{~mm}$. Consent was taken for vaginal examination, hysteroscopic diagnostic dilatation and curettage under general anesthesia. Speculum examination revealed a cauliflower like growth measuring about $6 \times 6 \mathrm{~cm}$ arising from the cervix and a diagnosis of cervical polyp was made. Bimanual examination revealed normal sized uterus with no adnexal pathology. Polypectomy and hysteroscopic dilatation and curettage was done in view of cervical polyp and thickened endometrium (Figure 1). Histopathological report showed a polypoid fragment with leaf like structures which is composed of hypercellular stroma lined by single layer of benign looking epithelial cells. There are scattered glands within a hypercellular stroma with the cells displaying oval to spindle-shaped nuclei with mild pleomorphic and distinct nucleoli (Figures 2 and 3). Around three mitotic figures were noticed in ten high power fields. Immunohistochemical stains showed the mesenchymal cells are diffusely positive for CD10 (Figure 4), Actin (Figure 5) and Desmin panCK (Figure 6) which highlighted the epithelial component. No tumor necrosis, heterologous components or lymphovascular permeation were identified. The diagnosis of cervical polyp with features of well differentiated Müllerian adenosarcoma of low grade with endometrium in secretory phase was given. She was then referred to our hospital -Government hospital Melaka - for further management. Computed tomography (CT) scan of abdomen and pelvis was done which showed an enlarged uterus with hydrometra and involvement of cervix could not be ruled out as it was bulky. There were bilateral ovarian cysts measuring less than $3 \times 3 \mathrm{~cm}$ and no ascites. No evidence of distant metastasis.

The diagnosis of adenosarcoma was revealed to the patient and her parents. After a thorough evaluation of available literature and extensive discussions with the family members, a decision was made to perform radical

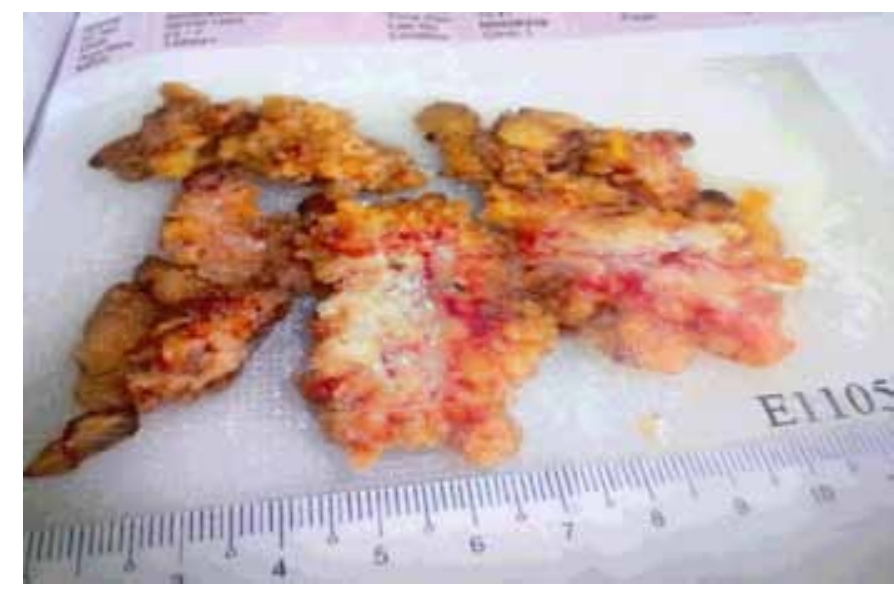

Figure 1: Tissue after polypectomy. It was removed in pieces.

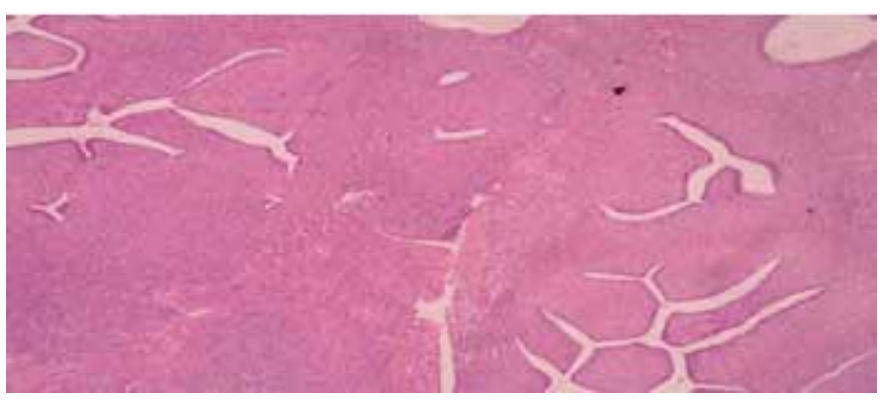

Figure 2: Microscopic picture of the polyp with scattered glands within a hypercellular stroma with the cells displaying oval to spindle-shaped nuclei with mild pleomorphic and distinct nucleoli (H\&E stain, $\mathrm{x} 400$ ).

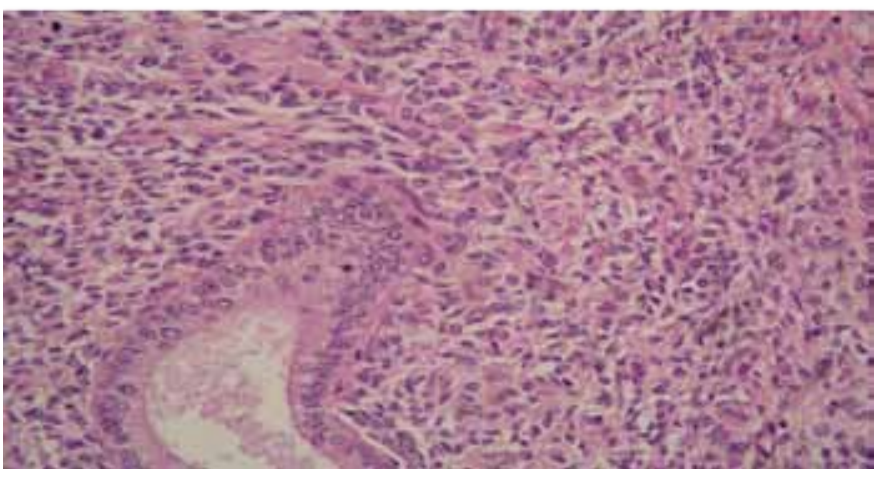

Figure 3: Higher magnification of the tumor showing mild nuclear atypia (H\&E stain, $\mathrm{x} 400$ ). 


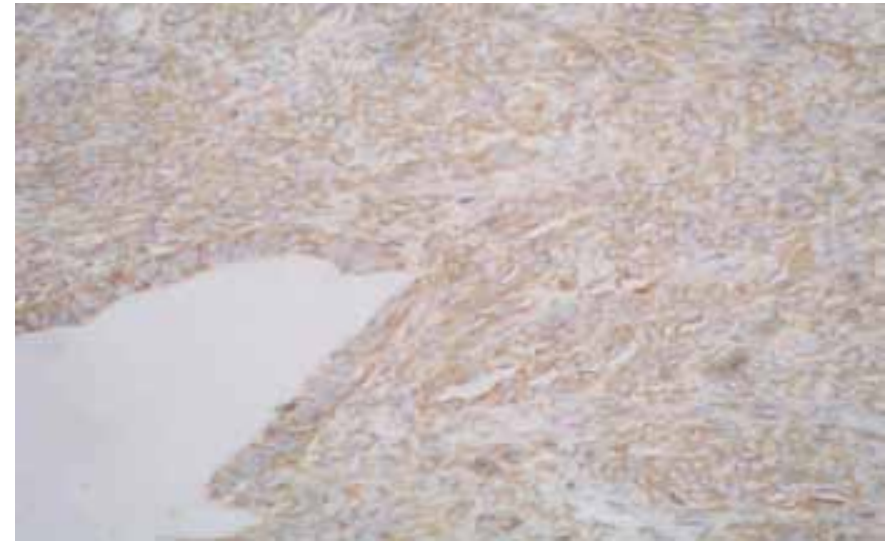

Figure 4: Immunohistochemical stains showing the mesenchymal cells are diffusely positive for CD10 which highlights the epithelial component (CD10, x400).

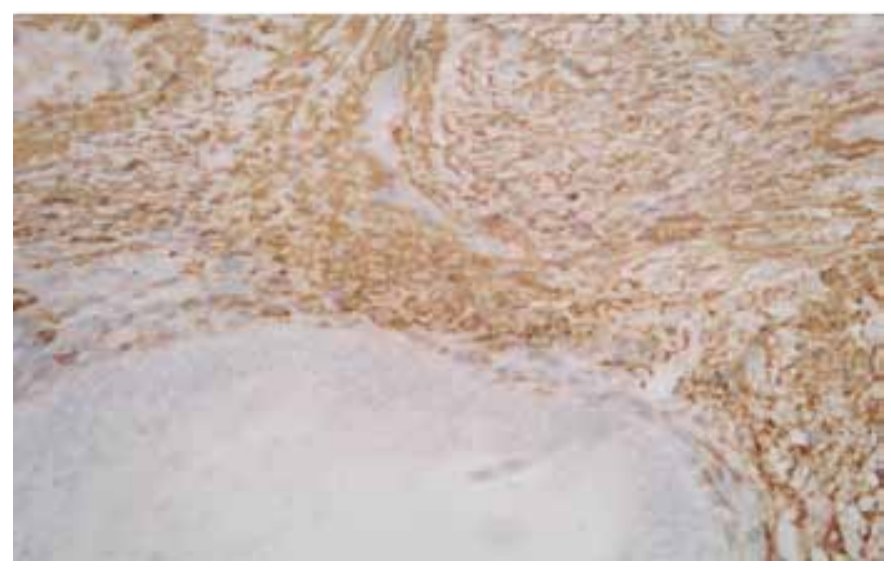

Figure 5: Immunohistochemical stains showing the mesenchymal cells are diffusely positive for Actin which highlights the epithelial component (Actin, x400).

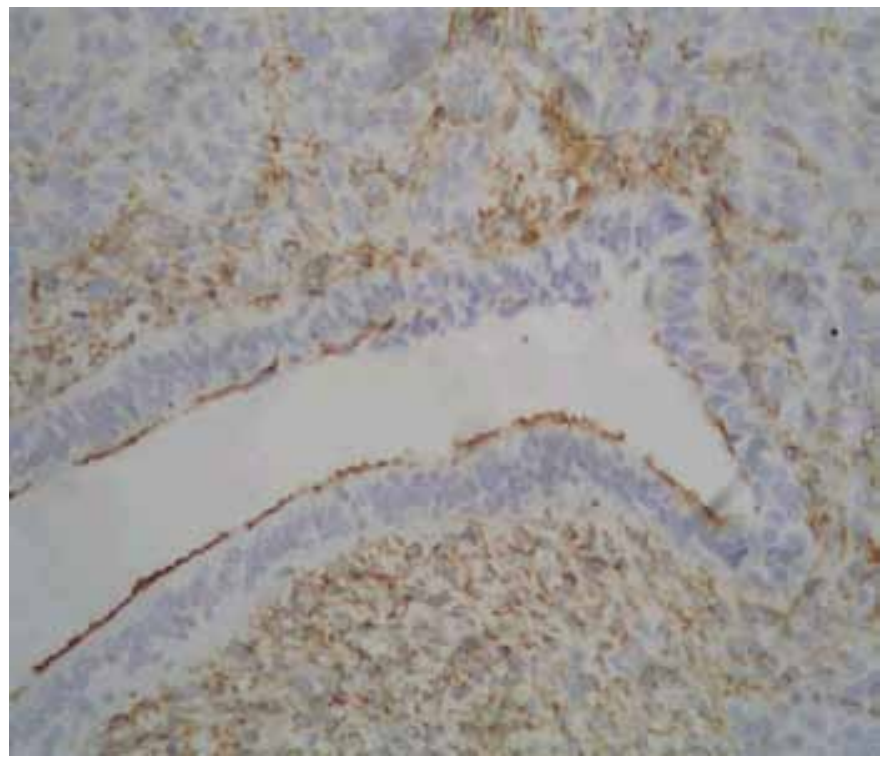

Figure 6: Immunohistochemical stains showing the mesenchymal cells are diffusely positive for Desmin, panCK highlights the epithelial component (panCK, x400). surgery of the patient. After consented for operation, exploratory laparotomy was carried out. Intraoperatively, a bulky uterus corresponding to 8-10 weeks size of gravid uterus, left endometriotic cyst measuring about $2.6 \times 3.0 \mathrm{~cm}$ with normal looking right ovary and a small tumor mass measuring about $3 \mathrm{~cm}$ on the surface of small bowel, which is $4 \mathrm{~cm}$ from the ileocecal junction were found. Intraabdominal findings were suggestive of an extensive disease/involvement, which warranted our team to proceed with radical surgery in this patient. A total abdominal hysterectomy, bilateral salpingooophorectomy, omentectomy, pelvic and paraaortic lymphadenectomy, appendicectomy, a $5^{-\mathrm{cm}}$ resection of small bowel and end-to-end anastomosis were done and peritoneal fluid was sent for cytological study. Her postoperative period was uneventful. She had been clinically free of the disease for 18 months since surgery. Currently, she is on Premarin $0.625 \mathrm{mg}$ once daily and other supplements. Although there are complaints of vague body ache, fatigue and mood-swings, patient is coping well with the treatment given.

Patient is being regularly followed-up once in every 4 months with pelvic examination and ultrasound of abdomen. Histopathological report showed the following findings:

Gross: A brownish mass of $15 \mathrm{~mm}$ size at the right endometrial wall with no obvious myometrial invasion, gross involvement of lower uterus, endocervix or parametrium. There are two polyps at the uterine fundus measuring $15 \times 5 \times 5 \mathrm{~mm}$ and $10 \times 5 \times 5 \mathrm{~mm}$. Left ovary is slightly enlarged measuring 30x30x25 mm. Other structures were normal.

Microscopy: No residual tumor mass in uterus and cervix. Two benign endometrial polyps, left follicular ovarian cyst, right benign inclusion cyst of ovary and heterotopias of pancreatic tissue over the surface of small bowel. No evidence of malignancy. Peritoneal fluid study is negative for malignancy.

\section{DISCUSSION}

A malignant mixed Müllerian tumor is a malignant neoplasm found in the uterus, ovaries, fallopian tubes and other parts of the body that contains both carcinomatous (epithelial tissue) and sarcomatous (connective tissue) components. It is divided into homologous and a heterologous type. A malignant mixed Müllerian tumor (MMMT) account for 2-5\% of all tumors derived from the uterus. It is found predominantly in postmenopausal women. Risk factors are similar to those of adenocarcinomas and include obesity, exogenous estrogen therapies and nulliparity. Uterine adenosarcoma occurs in all age groups, but is most common in women after the menopause [8]. Adenosarcoma most commonly arises from the endometrium, but some cases are situated in the endocervix [9]. In postmenarchal adolescents, these polypoid tumors usually arise from the cervix, 
in contrast to postmenopausal women in whom they usually arise from the endometrium. Tumors that arise in the cervix account for $2 \%$ of all adenosarcoma of the female genital tract (71\% endometrium, $15 \%$ ovary and $12 \%$ the pelvis) [10]. The common presenting symptom is abnormal vaginal bleeding followed by pelvic pain, an abdominal mass or vaginal discharge. Its association is also described in patients taking tamoxifen and occasional cases have arisen in association with hyperestrogenism or with prior pelvic irradiation $[11,12]$. Patient may present with intermenstrual and postcoital bleeding [13]. Clinical diagnosis may be challenging due to the benign gross appearance of the polyps [14]. Pathological diagnosis of low-grade adenosarcoma is often difficult in a tiny histological specimen. Most of the time, the sarcomatous stroma may be of very low grade and may be misdiagnosed as a benign disease such as adenofibroma $[15,16]$.

The differential diagnosis of adenosarcoma includes benign polyp, adenofibroma, embryonal rhabdomyosarcoma and endometrial stromal sarcoma. Cervical Müllerian adenosarcoma is usually treated by radical hysterectomy even in young age group as there is high recurrence rate following conservative surgical management [7]. Recurrences may occur late. The role of chemotherapy and radiation is limited in the absence of extensive pelvic or residual disease [17]. Since the CT scan finding and intra-abdominal findings during surgery were suggestive of an extensive disease/involvement, which warranted radical surgery in our patient. However, histopathology report revealed no residual tumor mass in the cervix and uterus. So she has not received any adjuvant chemotherapy or radiotherapy. The patient and her family members were informed about the histopathological findings. Poor prognostic factors include sarcomatous overgrowth and high-grade malignant features in the stromal component. The presence of malignancy should be kept in mind always while resecting a cervical polyp.

\section{CONCLUSION}

Müllerian adenosarcoma of the endocervix is rare in young women. The appropriate treatment of this tumor is uncertain because of its rarity in this age group, the malignant potential is not clearly defined and the evidence about the management is limited. On literature review, conservative surgical management such as polypectomy, cone biopsy or trachelectomy had more chance of recurrence. Hence, most of the experts recommend definite or radical surgical management irrespective of the age and parity. Chemotherapy and radiation is not recommended in the absence of extensive pelvic and/ or residual disease. From literature review, recurrences have been reported 11 years after conservative treatment. Recurrences may occur late and thus long-term follow-up of these patients is recommended.

\section{Author Contributions}

Sameera Begum - Substantial contributions to conception and design, Acquisition of data, Drafting the article, Revising it critically for important intellectual content, Final approval of the version to be published

Prasanta kumar Deka - Substantial contributions to conception and design, Acquisition of data, Drafting the article, Final approval of the version to be published Tham Seng Woh - Substantial contributions to conception and design, Acquisition of data, Final approval of the version to be published

\section{Guarantor}

The corresponding author is the guarantor of submission.

\section{Conflict of Interest}

Authors declare no conflict of interest.

\section{Copyright}

(C) Sameera Begum et al. 2013; This article is distributed under the terms of Creative Commons attribution 3.0 License which permits unrestricted use, distribution and reproduction in any means provided the original authors and original publisher are properly credited. (Please see www.ijcasereportsandimages.com/copyright-policy.php for more information.)

\section{REFERENCES}

1. Mayumi Takeuchi, Kenji Matsuzaki, Shusaku Yoshida, et al. Adenosarcoma of the uterus: Magnetic resonance imaging characteristics. Clin Imaging 2009 May-Jun;33(3):244-7.

2. Clement PB, Scully RE. Müllerian adenosarcoma of the uterus. A clinicopathologic analysis of ten cases of a distinctive type of müllerian mixed tumor. Cancer 1974 Oct;34(4):1138-49.

3. Clement PB, Scully RE. Extrauterine mesodermal (müllerian) adenosarcoma: A clinicopathologic analysis of five cases. Am J Clin Pathol 1978 Mar;69(3):276-83.

4. Dincer AD, Timmins P, Pietrocola D, Fisher $\mathrm{H}$, Ambrose RA. Primary peritoneal mullerian adenosarcoma with sarcomatous overgrowth associated with endometriosis: A case report. Int $\mathrm{J}$ Gynecol Pathol 2002 Jan;21(1):65-8.

5. Eichhorn JH, Young RH, Clement PB, Schully RE. Mesodermal (mullerian) adenosarcoma of the ovary: A clinicopathologic analysis of 40 cases and a review of the literature. Am J Surg Pathol 2002 Oct;26(10):1243-58.

6. Murugasu A, Miller J, Proietto A, Millar E. Extragenital mullerian adenosarcoma with sarcomatous overgrowth arising in an endometriotic cyst in the pouch of Douglas. Int $\mathrm{J}$ Gynecol Cancer 2003 MayJun;13(3):371-5.

7. Nathalie A. Fleming, Laura Hopkins, Joseph de Nanassy, Mary Senterman, Amanda Y. Black. Mullerian adenosarcoma of the cervix in a 10-year-old 
girl: Case report and review of the literature. J Pediatr Adolesc Gynecol 2009 Aug;22(4):e45-1.

8. McCluggage WG. Mullerian Adenosarcoma of the Female Genital Tract. Advances in Anatomic Pathology 2010 Mar;17(2):122-9.

9. Oda Y, Nakanishi I, Tateiwa T. Intramural Mullerian adenosarcoma of the uterus with adenomyosis. Arch Pathol Lab Med 1984 Oct;108(10):798-1.

10. Verschraegen CF, Vasuratna A, Edwards C, et al. Clinicopathological analysis of mullerian adenosarcoma: The M.D. Anderson Cancer Center experience. Oncol Rep 1998 Jul-Aug;5(4):939-44.

11. Clement PB, Scully RE. Mullerian adenosarcoma of the uterus: A clinicopathologic analysis of 100 cases with a review of the literature. Hum Pathol 1990 Apr;21(4):363-81.

12. Clement PB, Oliva E, Young RH. Mullerian adenosarcoma of the uterine corpus associated with tamoxifen therapy: A report of six cases and a review of tamoxifen-associated endometrial lesions. Int $\mathrm{J}$ Gynecol Pathol 1996 Jul;15(3):222-9.
13. Manoharan M, Azmi MA, Soosay G, Mould T, Weekes AR. Mullerian adenosarcoma of uterine cervix: Report of three cases and review of literature. Gynecologic Oncology 2007 Apr;105(1):256-60.

14. Chin P, Lim Y, Chia Y, Yam K. Mullerian adenosarcoma of the uterine cervix: A case series in an Asian population. International Journal of Gynecology \& Obstetrics 2009;107S2:S691-2. [Poster presentations].

15. Gollard R, Kosty M, Bordin G, Wax A, Lacey C. Two unusual presentations of müllerian adenosarcoma: case reports, literature review, and treatment considerations. Gynecol Oncol 1995 Dec;59(3):412-2.

16. Inoue M, Fukuda H, Tanizawa O. Adenosarcomas originating from sites other than uterine endometrium. Int J Gynaecol Obstet 1995 Mar;48(3):299-306.

17. Ramos P, Ruiz A, Carabias E, Piñero I, Garzon A, Alvarez I. Mullerian adenosarcoma of the cervix with heterologous elements: report of a case and review of the literature. Gynecol Oncol 2002 Jan;84(1):161-6.
Access full text article on other devices

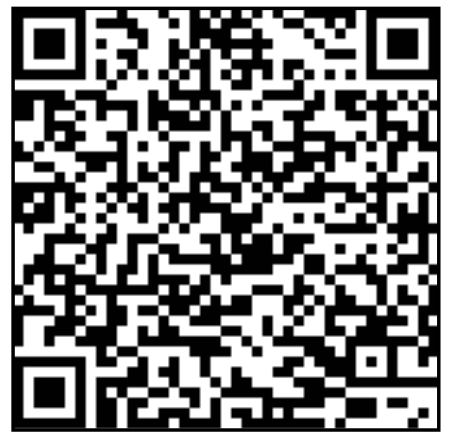

Access PDF of article on other devices

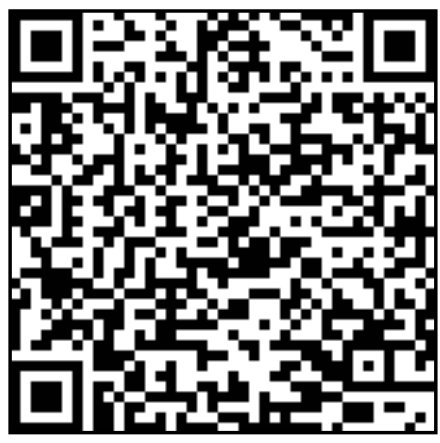

